\title{
Genome-wide association study identifies novel loci for type 2 diabetes-attributed end-stage kidney disease in African Americans
}

Meijian Guan ${ }^{1,2}$, Jacob M. Keaton ${ }^{1,2}$, Latchezar Dimitrov ${ }^{1,2}$, Pamela J. Hicks ${ }^{1,2}$, Jianzhao Xu $u^{1,2}$, Nicholette D. Palmer ${ }^{1,2,3}$, Lijun Ma ${ }^{4}$, Swapan K. Das ${ }^{5}$, Yii-Der I. Chen ${ }^{6}$, Josef Coresh ${ }^{7}$, Myriam Fornage ${ }^{8}$, Nora Franceschini ${ }^{9}$, Holly Kramer ${ }^{10,11}$, Carl D. Langefeld ${ }^{12,13}$, Josyf C. Mychaleckyj ${ }^{14}$, Rulan S. Parekh ${ }^{15}$, Wendy S. Post ${ }^{7}$, Laura J. Rasmussen-Torvik ${ }^{16}$, Stephen S. Rich ${ }^{14}$, Jerome I. Rotter ${ }^{6,17}$, John R. Sedor ${ }^{18,19}$, Denyse Thornley-Brown ${ }^{20}$, Adrienne Tin ${ }^{7}$, James G. Wilson ${ }^{21}$, Barry I. Freedmann ${ }^{4}$, Donald W. Bowden ${ }^{1,2,3}$, Maggie C. Y. $\mathrm{Ng}^{1,2,3^{*}}$ and FIND Consortium

\begin{abstract}
Background: End-stage kidney disease (ESKD) is a significant public health concern disproportionately affecting African Americans (AAs). Type 2 diabetes (T2D) is the leading cause of ESKD in the USA, and efforts to uncover genetic susceptibility to diabetic kidney disease (DKD) have had limited success. A prior genome-wide association study (GWAS) in AAs with T2D-ESKD was expanded with additional AA cases and controls and genotypes imputed to the higher density 1000 Genomes reference panel. The discovery analysis included 3432 T2D-ESKD cases and 6977 non-diabetic non-nephropathy controls $(N=10,409)$, followed by a discrimination analysis in 2756 T2D nonnephropathy controls to exclude T2D-associated variants.
\end{abstract}

Results: Six independent variants located in or near RND3/RBM43, SLITRK3, ENPP7, GNG7, and APOL1 achieved genome-wide significant association $\left(P<5 \times 10^{-8}\right)$ with T2D-ESKD. Following extension analyses in 1910 nondiabetic ESKD cases and 908 non-diabetic non-nephropathy controls, a meta-analysis of 5342 AA all-cause ESKD cases and 6977 AA non-diabetic non-nephropathy controls revealed an additional novel all-cause ESKD locus at EFNB2 (rs77113398; $P=9.84 \times 10^{-9} ; O R=1.94$ ). Exclusion of $A P O L 1$ renal-risk genotype carriers identified two additional genome-wide significant T2D-ESKD-associated loci at GRAMD3 and MGAT4C. A second variant at GNG7 (rs373971520; $P=2.17 \times 10^{-8}, O R=1.46$ ) remained associated with all-cause ESKD in the APOL1-negative analysis.

Conclusions: Findings provide further evidence for genetic factors associated with advanced kidney disease in AAs with T2D.

Keywords: African Americans, Genome-wide association study, Type 2 diabetes, Diabetic kidney disease, End-stage kidney disease

\footnotetext{
* Correspondence: maggie.ng@vumc.org

${ }^{1}$ Center for Genomics and Personalized Medicine Research, Wake Forest

School of Medicine, Winston-Salem, NC, USA

${ }^{2}$ Center for Diabetes Research, Wake Forest School of Medicine,

Winston-Salem, NC, USA

Full list of author information is available at the end of the article
}

C The Author(s). 2019 Open Access This article is distributed under the terms of the Creative Commons Attribution 4.0 International License (http://creativecommons.org/licenses/by/4.0/), which permits unrestricted use, distribution, and reproduction in any medium, provided you give appropriate credit to the original author(s) and the source, provide a link to the Creative Commons license, and indicate if changes were made. The Creative Commons Public Domain Dedication waiver (http://creativecommons.org/publicdomain/zero/1.0/) applies to the data made available in this article, unless otherwise stated. 


\section{Introduction}

Increasing evidence suggests that genetic factors play a major role in susceptibility to end-stage kidney disease (ESKD). This is particularly relevant in African Americans (AAs) where incidence rates of ESKD are more than threefold greater than European Americans (EAs) [1]. The mortality rates for ESKD, dialysis, and transplant patients are 136, 166, and 30 per 1000 patient-years, respectively, and account for $7.2 \%$ of Medicare-paid claims costs [1]. Diabetes, of which $95 \%$ of patients have type 2 diabetes (T2D), remains the leading reported cause of ESKD in the USA accounting for $>44 \%$ of cases [1]. Improvements in glycemic, lipid, and blood pressure control have not markedly reduced the prevalence of diabetic kidney disease (DKD) [1, 2]. In addition, familial aggregation of DKD is independent from socioeconomic status and established environmental risk factors $[3,4]$. Although the G1 and G2 alleles in the apolipoprotein L1 gene (APOL1) contribute to $50-70 \%$ of non-diabetic ESKD in AAs, they do not fully explain the excess risk of T2D-attributed ESKD (T2D-ESKD) in this population [5-7].

Genome-wide association studies (GWAS) have identified $>70$ genome-wide significant variants associated with chronic kidney disease (CKD), albuminuria, or renal function in European ancestry populations [8-11]. However, few loci were associated with DKD in diverse populations and they do not consistently replicate, in part due to limited sample sizes [12-18]. The etiology of kidney complications in patients with T2D is likely more heterogeneous than in patients with type 1 diabetes [16]. Therefore, careful phenotyping and larger sample sizes are required to improve statistical power. To explore the genetic architecture of advanced kidney disease in T2D, we extended our previous GWAS (2890 ESKD patients and 1719 non-diabetic nonnephropathy controls) efforts in a larger sample of AAs with severe kidney disease. Association analyses were performed in six independent AA cohorts (Wake Forest School of Medicine, WFSM; Family Investigation of Nephropathy and Diabetes, FIND; Atherosclerosis Risk in Communities Study, ARIC; Multi-Ethnic Study of Atherosclerosis, MESA; Jackson Heart Study, JHS; and Coronary Artery Risk Development in Young Adults, CARDIA) for T2D-ESKD or non-diabetic ESKD through a multi-stage study design (Fig. 1). This encompassed 15,075 AAs classified into four phenotypic groups: T2D-ESKD cases $(N=$ 3432), non-diabetic non-nephropathy controls $(N=6977)$, T2D-lacking nephropathy controls $(N=2756)$, and nondiabetic ESKD cases $(N=1910)$.

In the discovery stage, GWAS was performed in 3432 T2D-ESKD cases and 6977 non-diabetic non-nephropathy controls, followed by a discrimination analysis to exclude T2D-associated loci in 2756 T2D non-nephropathy controls. Extension analyses were performed in 1910 AAs with non-diabetic ESKD and 908 non-nephropathy controls to assess the contribution of T2D-ESKD-associated loci to non-diabetic kidney disease. A meta-analysis of diabetic and non-diabetic ESKD cases assessed genetic associations in all-cause ESKD. APOL1-associated forms of

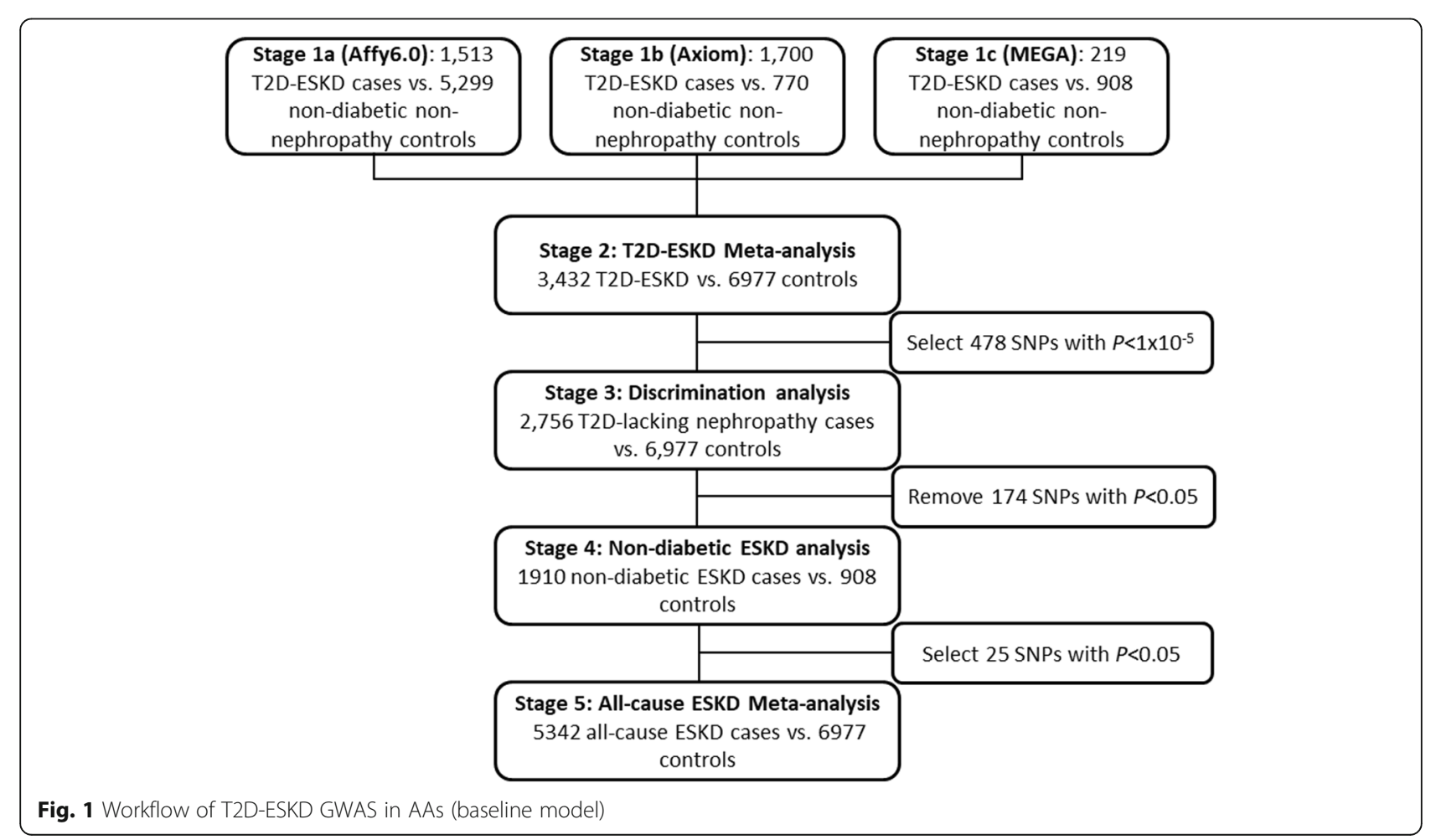


non-diabetic kidney disease and T2D often co-exist in patients. As such, many diabetic patients with kidney disease may be misclassified as having DKD, since diagnostic kidney biopsies are usually not performed. Herein, a second GWAS analysis excluding individuals with APOL1 renal-risk genotypes was performed to minimize misclassification of T2D-ESKD.

\section{Results}

\section{Study overview}

This study has $>80 \%$ power to detect common variants (MAF $\geq 0.10)$ with moderate effect $(O R \geq 1.3)$ at a significance level of $5 \times 10^{-8}$ (http://csg.sph.umich.edu/abecasis/ cats/). In all, seven genome-wide significant loci $(P<5 \times$ $10^{-8}$ ) associated with T2D-ESKD were identified in either the baseline model (RND3/RBM43, SLITRK3, ENPP7, GNG7, and APOL1) or APOL1-negative model (ENPP7, GRAMD3, and $M G A T 4 C$ ). In addition to $A P O L 1$, two loci, EFNB2 and GNG7, also reached genome-wide significance in the all-cause ESKD meta-analysis under either the baseline or APOL1-negative models.

\section{Clinical characteristics of study participants}

Tables 1 and 2 include detailed characteristics of study participants. ESKD cases were recruited from the WFSM (Affy6.0, Axiom, and MEGA), FIND, and ARIC studies. Individuals with T2D-ESKD or T2D-lacking nephropathy were older (or of similar age) compared to the non-diabetic non-nephropathy controls at recruitment. However, the average age at diagnosis of T2D in T2D-ESKD cases and T2D-lacking nephropathy controls were younger than nondiabetic non-nephropathy controls at recruitment. All T2D non-nephropathy controls and non-diabetic, non-nephropathy controls had normal eGFR $\geq 60 \mathrm{ml} / \mathrm{min} / 1.73 \mathrm{~m}^{2}$. In addition, non-diabetic non-nephropathy controls had fasting glucose levels $<126 \mathrm{mg} / \mathrm{dl}$. Controls with T2D-lacking nephropathy were more obese than T2D-ESKD or non-diabetic ESKD cases and non-diabetic, non-nephropathy controls, except that T2D-ESKD cases in ARIC were more obese than the other groups.

\section{Stage 1 and stage 2 T2D-ESKD association analysis}

In stage 1 discovery, GWAS was conducted separately in three datasets: (1) 1513 T2D-ESKD cases and 5299 nondiabetic non-nephropathy controls genotyped on Affy6.0, contributed by WFSM, FIND, ARIC, JHS, MESA, and CARDIA (stage 1a); (2) 1700 T2D-ESKD cases and 770 non-diabetic non-nephropathy controls from WFSM genotyped with Axiom Biobank genotyping array (stage 1b); and (3) 219 T2D-ESKD cases and 908 non-diabetic, non-nephropathy controls from WFSM genotyped on MEGA (stage 1c). A meta-analysis (stage 2) was performed to combine association results for 3432 T2D-ESKD cases and 6977 non-diabetic, non-nephropathy controls from stages 1a, 1b, and 1c. An inflation factor $\lambda$ of 1.013 was observed after correcting for genomic control (Additional file 1: Figure S1), suggesting that population structure and cryptic relatedness were sufficiently adjusted. Among variants demonstrating suggestive associations $\left(P<1 \times 10^{-5}\right), 59$ variants with $I^{2} \geq 80 \%$ were excluded due to high heterogeneity in effect sizes across studies. A total of 478 remaining variants were assessed in a discrimination analysis (81 of them achieved genome-wide significance; Additional file 1: Table S2).

\section{Stage 3 discrimination analysis}

To determine whether the T2D-ESKD associations identified in stage 1 meta-analysis were driven by association with T2D per se, a discrimination analysis was performed for T2D contrasting 2756 AAs with T2D-lacking nephropathy with 6977 non-diabetic non-nephropathy controls from stage 1 (Affy6.0, Axiom, MEGA; Additional file 1: Table S3). We subsequently excluded 174 of 478 T2D-ESK$\mathrm{D}$-associated variants nominally associated with T2D in the absence of nephropathy. Among the remaining T2D-ESKD associations, top variants representing 6 independent associations achieved genome-wide significance (Table 3, Fig. 2a). The strongest association was observed for rs9622363 located at $A P O L 1\left(P=1.42 \times 10^{-10}, \mathrm{OR}=0.77\right.$, $\mathrm{EAF}=0.45$ ). This variant was in moderate linkage disequilibrium $\left(r^{2}=0.33\right.$ and 0.34 , respectively in YRI) with the APOL1 G1 alleles (rs60910145, rs73885319) associated with non-diabetic ESKD [6]. The second strongest association was at rs58627064, an intergenic variant located near SLITRK3, $\left(P=6.81 \times 10^{-10}, \mathrm{OR}=1.62, \mathrm{EAF}=0.06\right)$. Two independent signals, $r s 142563193\left(P=1.24 \times 10^{-8}\right.$, OR $=$ $0.74, \mathrm{EAF}=0.23)$ and $\mathrm{rs} 142671759\left(P=5.53 \times 10^{-9}, \mathrm{OR}=\right.$ $2.26, \mathrm{EAF}=0.02)$ on chromosome 17 located near ENPP7, respectively, were also genome-wide significant. In addition, two associations with T2D-ESKD, rs4807299 ( $P=$ $\left.3.21 \times 10^{-8}, \mathrm{OR}=1.67, \mathrm{EAF}=0.05\right)$ located in GNG7 and rs72858591 $\left(P=4.54 \times 10^{-8}, \mathrm{OR}=1.43, \mathrm{EAF}=0.10\right)$ located in $R N D 3 / R B M 43$ were identified (Fig. 1a).

\section{Stage 4 non-diabetic ESKD analysis and stage 5 all-cause ESKD meta-analysis}

After the discrimination stage, 304 variants exhibiting suggestive association with T2D-ESKD $\left(P<1 \times 10^{-5}\right)$ were tested in 1910 independent non-diabetic ESKD cases and 908 controls from stage 1c. The goal of the stage 4 analysis was to evaluate the contribution of T2D-ESKD-associated loci to non-diabetic kidney disease. After excluding variants with heterogeneity $I^{2} \geq 80 \%$, 25 variants were nominally associated with non-diabetic ESKD $(P<0.05)$. Strong associations $\left(1.27 \times 10^{-29}<P<8.86 \times 10^{-15}\right)$ were observed in the APOL1-MYH9 region, confirming their role in non-diabetic kidney disease. An all-cause ESKD meta-analysis, including 5342 all-cause ESKD and 6977 non-diabetic 


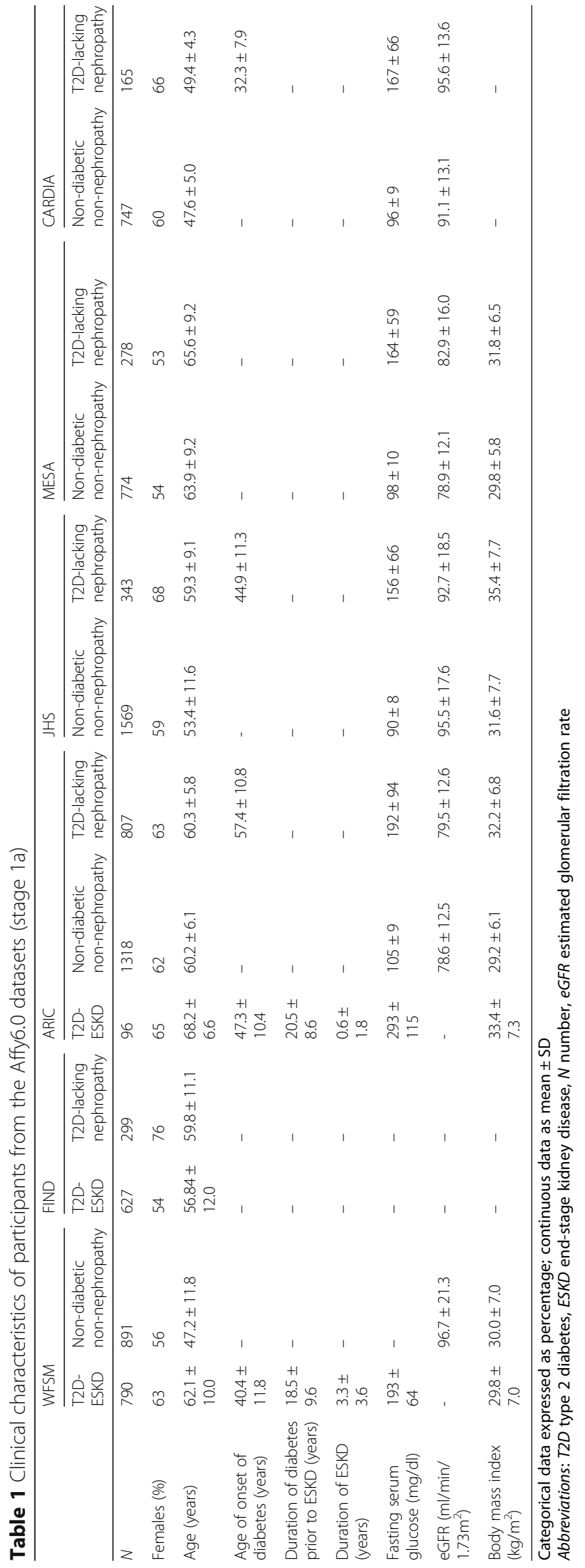


Table 2 Clinical characteristics of participants genotyped using Axiom and MEGA arrays (stage 1b and 1c)

\begin{tabular}{|c|c|c|c|c|c|c|c|}
\hline & \multicolumn{3}{|c|}{ WFSM-Axiom } & \multicolumn{4}{|c|}{ WFSM-MEGA } \\
\hline & $\begin{array}{l}\text { T2D- } \\
\text { ESKD }\end{array}$ & $\begin{array}{l}\text { Non-diabetic } \\
\text { non-nephropathy }\end{array}$ & $\begin{array}{l}\text { T2D-lacking } \\
\text { nephropathy }\end{array}$ & $\begin{array}{l}\text { T2D- } \\
\text { ESKD }\end{array}$ & $\begin{array}{l}\text { Non-diabetic } \\
\text { non-nephropathy }\end{array}$ & $\begin{array}{l}\text { T2D-lacking } \\
\text { nephropathy }\end{array}$ & $\begin{array}{l}\text { Non-diabetic } \\
\text { ESKD }\end{array}$ \\
\hline N & 1700 & 770 & 663 & 219 & 908 & 201 & 1910 \\
\hline Females (\%) & 56 & 49 & 64 & 49 & 59 & 62 & 41 \\
\hline Age (years) & $62.0 \pm 10.8$ & $47.9 \pm 12.0$ & $55.7 \pm 11.6$ & $62.0 \pm 11.0$ & $44.8 \pm 13.9$ & $55.8 \pm 9.5$ & $55.4 \pm 14.4$ \\
\hline Age of onset of diabetes (years) & $39.7 \pm 12.8$ & - & $46.2 \pm 12.3$ & $37.8 \pm 9.6$ & - & $43.7 \pm 10.3$ & - \\
\hline $\begin{array}{l}\text { Duration of diabetes prior to ESKD } \\
\text { (years) }\end{array}$ & $19.1 \pm 10.0$ & - & - & $20.4 \pm 9.5$ & - & - & - \\
\hline Duration of ESKD (years) & $3.6 \pm 3.6$ & - & - & $4.1 \pm 3.1$ & - & - & $6.2 \pm 5.8$ \\
\hline Fasting serum glucose (mg/dl) & $184 \pm 89$ & $96 \pm 22$ & $163 \pm 92$ & $127 \pm 33$ & $96 \pm 11$ & $174 \pm 62$ & $90 \pm 3$ \\
\hline $\operatorname{eGFR}\left(\mathrm{ml} / \mathrm{min} / 1.73 \mathrm{~m}^{2}\right)$ & - & $96.0 \pm 20.8$ & $91.3 \pm 19.7$ & - & $85.9 \pm 17.3$ & $95.2 \pm 17.3$ & - \\
\hline Body mass index $\left(\mathrm{kg} / \mathrm{m}^{2}\right)$ & $30.7 \pm 7.1$ & $29.6 \pm 7.4$ & $33.1 \pm 7.8$ & $30.8 \pm 7.0$ & $29.7 \pm 6.6$ & $33.0 \pm 6.5$ & $27.8 \pm 7.2$ \\
\hline
\end{tabular}

Categorical data expressed as percentage; continuous data as mean \pm SD

Abbreviations: T2D type 2 diabetes, ESKD end-stage kidney disease, $N$ number, eGFR estimated glomerular filtration rate

non-nephropathy controls, was conducted to evaluate the generalizability of the 25 T2D-ESKD-associated variants with broader forms of ESKD (stage 5). Thirty-five genome-wide significant variants at two loci were found to be associated with all-cause ESKD, including 15 variants within or near EFNB2 and 20 variants at APOL1 (Fig. 1b). The top association in APOL1 was rs9622363 $(P=1.96 \times$ $\left.10^{-25}, \mathrm{OR}=0.68, \mathrm{EAF}=0.43\right)$, and the top signal near EFNB2 was rs77113398 $\left(P=9.84 \times 10^{-9}, \mathrm{OR}=1.94, \mathrm{EAF}=\right.$ 0.023) (Table 4, Fig. 2b). Four additional independent loci demonstrated suggestive association $\left(P<5 \times 10^{-6}\right)$ with all-cause ESKD at LPP, FSTL5, OPRK1/ATPV1H, and $S Y B U / K C N V 1$ (Table 4, Fig. 2b).

\section{Association analysis excluding APOL1 renal-risk-genotype carriers}

A secondary analysis was performed excluding APOL1 renal-risk-genotype carriers in T2D-ESKD cases and non-diabetic non-nephropathy controls (APOL1-negative model) to enrich for T2D-associated ESKD. The baseline model showed a strong association of APOL1 and $M Y H 9$ with T2D-ESKD (Table 3, Fig. 1a) suggesting that some cases may have been misclassified and more likely had non-diabetic ESKD. A total of 664 T2D-ESKD cases and 918 non-diabetic non-nephropathy controls were excluded from stage 1 analysis, leaving 2768 T2D-ESKD cases and 6059 controls in the APOL1-negative model. Nominal associations with T2D-ESKD $(P<$ $1 \times 10^{-5}$ ) were observed with 522 variants (66 of them achieved genome-wide significance; Additional file 1: Table S2), and these were selected for stage 3 discrimination analysis. Two hundred twenty-three variants that had evidence of association with T2D per se (Additional file 1: Table S4) and 24 variants showing strong heterogeneity $\left(I^{2} \geq 80\right)$ in the meta-analysis were removed. Among the genome-wide significant variants identified in the baseline model, rs142671759 in ENPP7 $\left(P=4.10 \times 10^{-8}, \mathrm{OR}=2.30, \mathrm{EAF}=0.024\right)$ showed a consistent association with T2D-ESKD in the APOL1-negative model. Two additional variants reached genome-wide significance, rs75029938 in GRAMD3 $(P=$ $\left.2.02 \times 10^{-9}, \mathrm{OR}=1.89, \mathrm{EAF}=0.042\right)$ and $\mathrm{rs} 17577888$ in the MGAT4C region $\left(P=3.87 \times 10^{-8}, \mathrm{OR}=0.67, \mathrm{EAF}=\right.$ 0.087) (Table 5, Fig. 3a).

We further tested 275 suggestive T2D-ESKD associations that passed discrimination and had $I^{2}<80$ in 1019 additional AA non-diabetic ESKD cases that excluded APOL1 renal-risk-genotype carriers. Fifteen variants showed nominal evidence of association with non-diabetic ESKD. These were subsequently tested in an all-cause ESKD meta-analysis including 3787 all-cause ESKD cases and 6059 non-diabetic non-nephropathy controls of which APOL1 renal-risk-genotype carriers were excluded. A 2-base pair deletion in GNG7, rs373971520 $(P=2.17 \times$ $10^{-8}, \mathrm{OR}=1.46, \mathrm{EAF}=0.11$ ), achieved genome-wide significant association with all-cause ESKD (Fig. 3b). Seven additional loci displayed nominal association with all-cause ESKD $\left(P<5 \times 10^{-6}\right)$, including LPP, ALK/YPEL5, MNX1-AS1/UBE3C, NUP98, LINC01075/LINC00448, TMCO5A, and SULF2/LINC01522 (Table 6). The top associations from the baseline model had moderate attenuation in significance, despite the similar effect sizes, due in part to the reduced sample size (Additional file 1: Table S5).

In addition, a third GWAS was performed with $A P O L 1$ included as a covariate in the model (APO$L 1$-adjusted model) and comparing $-\log (P)$ values with baseline and APOL1-negative models. High correlation (Person correlation coefficient $r=0.95$ ) was observed between APOL1-adjusted and APOL1-negative models. The results of all three comparisons are included in the supplementary documentation (Additional file 1: Figure S2). 


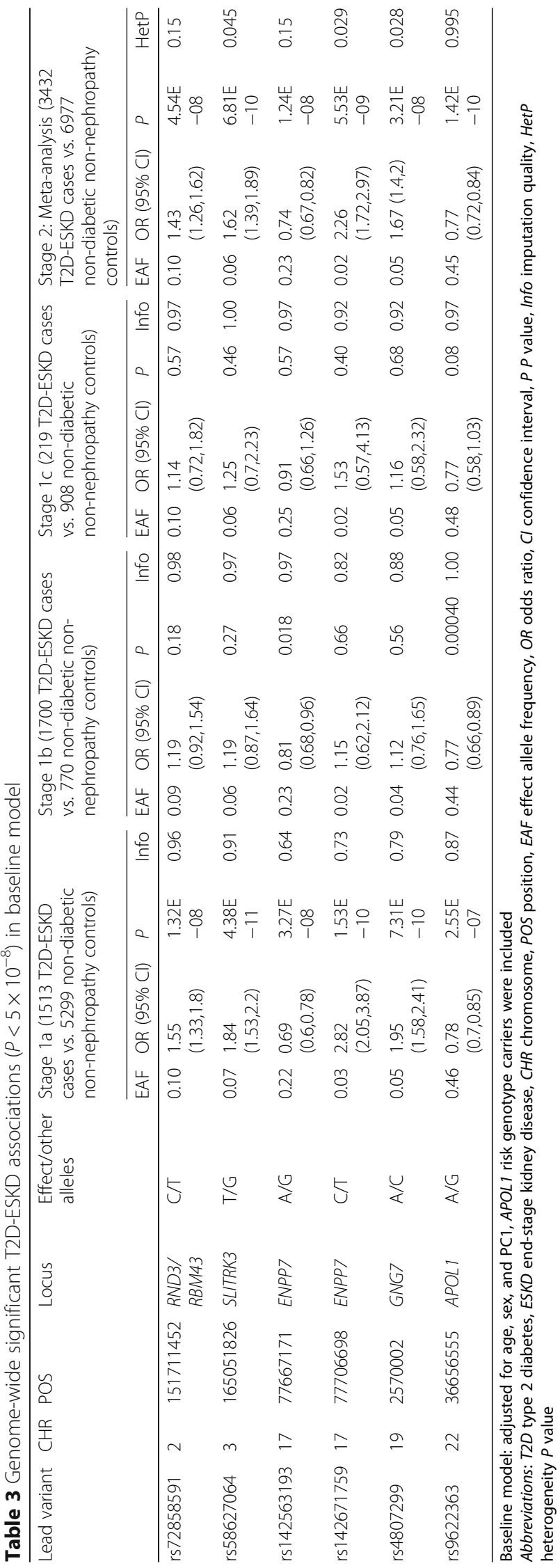



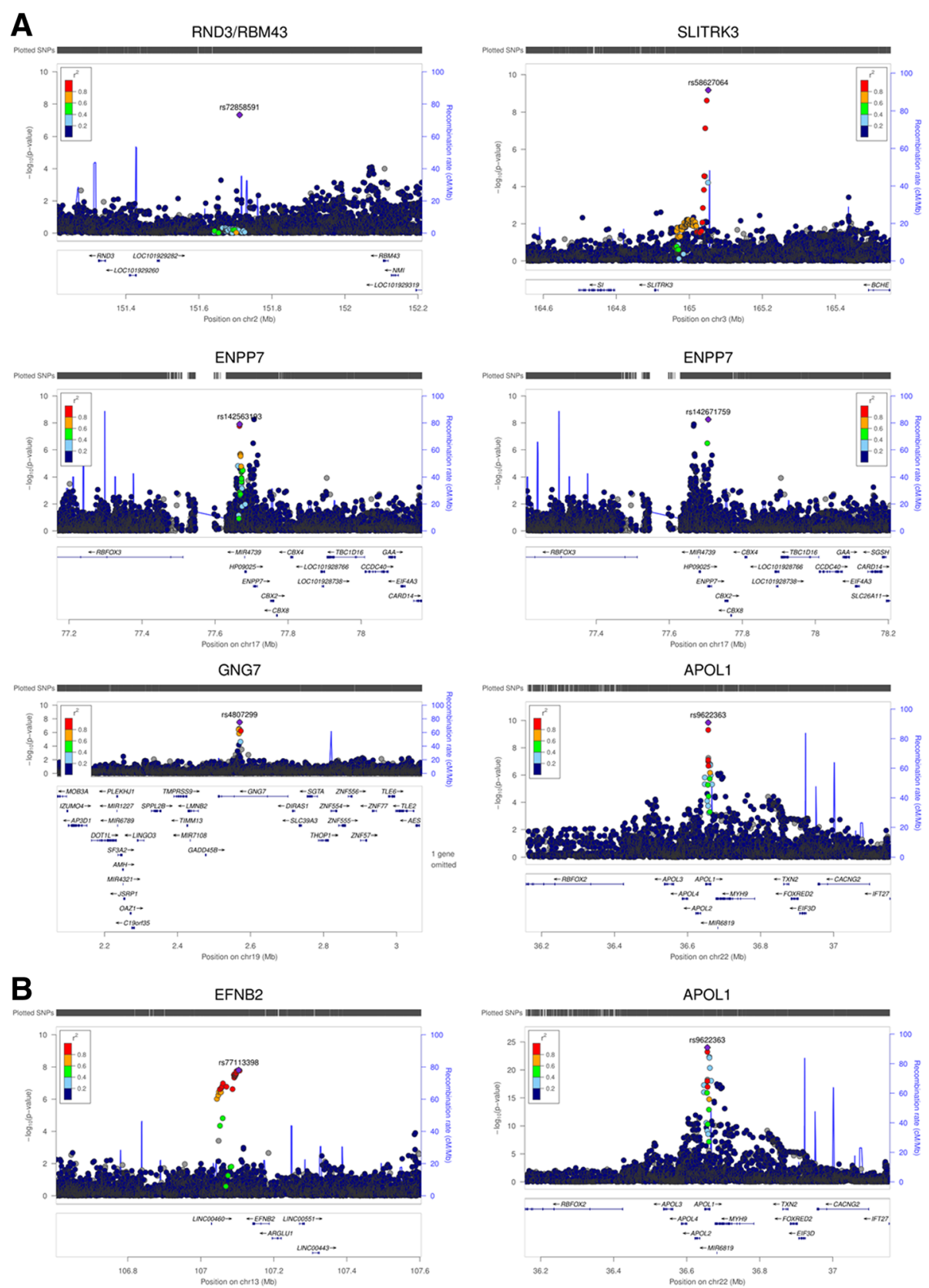

Fig. 2 Locus plots of genome-wide associations in the baseline model. a Locus plots of T2D-ESKD associations at $P<5 \times 10^{-8}$ in the baseline model. $\mathbf{b}$ Locus plots of all-cause ESKD-associated variants at $P<5 \times 10^{-8}$ in the baseline model. Abbreviations: T2D, type 2 diabetes; ESKD, endstage kidney disease; Baseline model: adjusted for age, sex, and PC1. APOL1 risk genotype carriers were included; reference genome: hg19/1000 Genomes Nov 2014 AFR.

\section{Discussion}

We report the results of a high-density GWAS investigating genetic susceptibility to T2D-ESKD in 15,075 AAs. Top variants associated with T2D-ESKD were subsequently assessed for association with non-diabetic ESKD, and a meta-analysis was performed to test for their generalizability to common forms of ESKD. Eight independent associations in seven genetic loci displayed genome-wide significant association with T2D-ESKD in the baseline or APOL1-negative models, including RND 3/RBM43, SLITRK3, ENPP7, GNG7, APOL1, GRAMD3, and MGAT4C. In addition to APOL1, two genome-wide significant loci were associated with all-cause ESKD, EFNB2 and GNG7. Further, 10 genetic loci demonstrated nominal association with all-cause $\operatorname{ESKD}(P<$ $\left.5 \times 10^{-6}\right)$, including LPP, FSTL5, OPRK1/ATP6V1H, 
Table 4 All-cause ESKD-associated variants at $P<5 \times 10^{-6}$ in baseline model

\begin{tabular}{|c|c|c|c|c|c|c|c|c|c|c|c|c|c|c|c|}
\hline \multirow[t]{2}{*}{ Lead variant } & \multirow[t]{2}{*}{$\mathrm{CHR}$} & \multirow[t]{2}{*}{ POS } & \multirow[t]{2}{*}{ Locus } & \multirow[t]{2}{*}{$\begin{array}{l}\text { Effect/other } \\
\text { alleles }\end{array}$} & \multirow[t]{2}{*}{ Info } & \multicolumn{3}{|c|}{$\begin{array}{l}\text { Stage } 2 \text { (3432 } \\
\text { T2D-ESKD cases } \\
\text { vs. } 6977 \text { non-diabetic } \\
\text { non-nephropathy } \\
\text { controls) }\end{array}$} & \multicolumn{3}{|c|}{$\begin{array}{l}\text { Stage } 4 \text { (1910 non- } \\
\text { diabetic ESKD cases } \\
\text { vs. } 908 \text { non-diabetic } \\
\text { non-nephropathy } \\
\text { controls) }\end{array}$} & \multicolumn{4}{|c|}{$\begin{array}{l}\text { Stage 5: Meta-analysis ( } 5342 \\
\text { all-cause ESKD cases vs. } 6977 \\
\text { non-diabetic non-nephropathy } \\
\text { controls) }\end{array}$} \\
\hline & & & & & & EAF & $\begin{array}{l}\text { OR }(95 \% \\
\mathrm{Cl})\end{array}$ & P & EAF & $\begin{array}{l}\text { OR }(95 \% \\
\mathrm{Cl})\end{array}$ & P & EAF & $\begin{array}{l}\text { OR }(95 \% \\
\mathrm{Cl})\end{array}$ & P & HetP \\
\hline rs76971802 & 3 & 188607071 & $\angle P P$ & $\mathrm{~T} / \mathrm{C}$ & 0.95 & 0.087 & $\begin{array}{l}1.35 \\
(1.19,1.54)\end{array}$ & $\begin{array}{l}8.66 \mathrm{E} \\
-06\end{array}$ & 0.084 & $\begin{array}{l}1.42 \\
(1.08,1.87)\end{array}$ & 0.013 & 0.087 & $\begin{array}{l}1.35 \\
(1.2,1.52)\end{array}$ & $\begin{array}{l}1.36 \mathrm{E} \\
-06\end{array}$ & 0.86 \\
\hline rs5863506 & 4 & 162909217 & FSTL5 & $\mathrm{TA} / \mathrm{T}$ & 0.96 & 0.33 & $\begin{array}{l}1.22 \\
(1.12,1.32)\end{array}$ & $\begin{array}{l}1.64 \mathrm{E} \\
-06\end{array}$ & 0.33 & $\begin{array}{l}1.19 \\
(1.01,1.40)\end{array}$ & 0.033 & 0.33 & $\begin{array}{l}1.21 \\
(1.12,1.30)\end{array}$ & $\begin{array}{l}4.57 \mathrm{E} \\
-07\end{array}$ & 0.87 \\
\hline rs141746998 & 8 & 54310938 & $\begin{array}{l}\text { OPRK1/ } \\
\text { ATP6V1H }\end{array}$ & CAT/C & 0.94 & 0.031 & $\begin{array}{l}0.62 \\
(0.5,0.76)\end{array}$ & $\begin{array}{l}9.40 \mathrm{E} \\
-06\end{array}$ & 0.034 & $\begin{array}{l}0.61 \\
(0.39,0.93)\end{array}$ & 0.022 & 0.031 & $\begin{array}{l}0.61 \\
(0.5,0.75)\end{array}$ & $\begin{array}{l}1.44 \mathrm{E} \\
-06\end{array}$ & 0.96 \\
\hline rs11997465 & 8 & 110891977 & $\begin{array}{l}\text { SYBU/ } \\
\text { KCNV1 }\end{array}$ & $\mathrm{C} / \mathrm{G}$ & 0.99 & 0.28 & $\begin{array}{l}1.22 \\
(1.12,1.33)\end{array}$ & $\begin{array}{l}3.21 \mathrm{E} \\
-06\end{array}$ & 0.28 & $\begin{array}{l}1.21 \\
(1.02,1.43)\end{array}$ & 0.026 & 0.28 & $\begin{array}{l}1.22 \\
(1.13,1.31)\end{array}$ & $\begin{array}{l}6.72 \mathrm{E} \\
-07\end{array}$ & 0.65 \\
\hline rs77113398 & 13 & 107103906 & EFNB2 & $\mathrm{A} / \mathrm{G}$ & 0.93 & 0.023 & $\begin{array}{l}1.94 \\
(1.52,2.47)\end{array}$ & $\begin{array}{l}1.25 \mathrm{E} \\
-07\end{array}$ & 0.021 & $\begin{array}{l}1.87 \\
(1.08,3.24)\end{array}$ & 0.025 & 0.023 & $\begin{array}{l}1.94 \\
(1.55,2.43)\end{array}$ & $\begin{array}{l}9.84 \mathrm{E} \\
-09\end{array}$ & 0.96 \\
\hline rs9622363 & 22 & 36656555 & APOL1 & $A / G$ & 0.95 & 0.45 & $\begin{array}{l}0.77 \\
(0.72,0.84)\end{array}$ & $\begin{array}{l}1.42 \mathrm{E} \\
-10\end{array}$ & 0.35 & $\begin{array}{l}0.42 \\
(0.36,0.48)\end{array}$ & $4.32 \mathrm{E}-29$ & 0.43 & $\begin{array}{l}0.68 \\
(0.64,0.73)\end{array}$ & $\begin{array}{l}1.96 \mathrm{E} \\
-25\end{array}$ & $\begin{array}{l}1.14 \mathrm{E} \\
-09\end{array}$ \\
\hline
\end{tabular}

Baseline model: adjusted for age, sex, and PC1; APOL1 risk genotype carriers were included

Abbreviations: T2D type 2 diabetes, ESKD end-stage kidney disease, CHR chromosome, $P O S$ position, EAF effect allele frequency, OR odds ratio, $C I$ confidence interval, $P, P$ value, Info average imputation quality, Het $P$ heterogeneity $P$ value

SYBU/KCNV1, ALK/YPEL5, MNX1-AS1/UBE3C, NUP 98, LINC01075/LINC00448, TMCO5A, and SULF2/LIN C01522.

The most significant association with T2D-ESKD $(\mathrm{OR}=$ 0.77, $\left.P=1.42 \times 10^{-10}\right)$ and all-cause ESKD (OR $=0.69, P=$ $\left.1.96 \times 10^{-25}\right)$ in the baseline model was an intronic variant rs9622363 in the APOL1 region associated with non-diabetic kidney disease in individuals with African ancestry. Conditioning on the APOL1 G1 and G2 alleles dramatically diminishes its significance [6]. rs9622363 is reported to alter transcription factor (TF) binding motifs (Additional file 1: Table S6). In a recent study, rs9622363 and APOL1 G1 alleles formed a haplotype that achieved the strongest association with CKD in Nigerians [19]. Unlike G1 or G2, the major allele in rs9622363 $(\mathrm{G}, \mathrm{EAF}=0.57)$ is associated with the risk of CKD. After excluding APOL1 renal-risk-genotype carriers, association with rs9622363 was attenuated. This confirmed that rs9622363 and APOL1 G1 and G2 alleles contribute to the same signal. Identification of rs9622363 in the baseline model may suggest misclassification of some cases as T2D-ESKD.

An intergenic variant (rs72858591) located between a GTPase protein gene RND3 and RBM43, encoding RNA binding motif protein 43 , revealed genome-wide significant association with T2D-ESKD. It is associated with TF binding motif changes and overlap with both promoter and enhancer regions (Additional file 1: Table S6). An independent intergenic variant $\left(\mathrm{rs} 7560163, r^{2}=0.01\right.$, YRI) in this region was previously associated with T2D in AAs [20]. In contrast, rs72858591 was not associated with T2D $(P=0.073)$ in the present study. This may suggest that two different sets of variations in this locus independently contribute to T2D and T2D-ESKD, a possible pleiotropic effect. Two independent variants (rs142563193 and rs142671759) that were genome-wide significantly associated with T2D-ESKD are located near ENPP7. These variants overlap with enhancer and promoter regions, DNase hypersensitive peaks, and/or TF binding motifs (Additional file 1: Table S6). The protein encoded by ENPP7 is an intestinal alkaline sphingomyelin phosphodiesterase that converts sphingomyelin to ceramide and phosphocholine. ENPP7 reportedly affects cholesterol absorption [21], and numerous studies suggest that high-density lipoprotein cholesterol levels are risk factors for CKD in patients with diabetes [22-24].

Two variants located in GNG7 were associated with either T2D-ESKD (rs4807299; $P=3.21 \times 10^{-8}$, baseline model) or all-cause ESKD (rs373971520; $P=2.17 \times 10^{-8}$; APOL1-negative model). Rs4807299 is associated with TF binding motif changes and overlaps with both promoter and enhancer regions (Additional file 1: Table S6). GNG7 encodes G Protein Subunit Gamma 7, involved in central nervous system function [25] and cancer risk [26, 27].

Since African Americans with diabetes and proteinuria often do not get a diagnostic kidney biopsy, their ESKD is typically presumed to have been caused by DKD. However, APOL1-associated non-diabetic kidney disease may be the true cause of kidney disease in many such patients. Analyses excluding $A P O L 1$ renal-risk-genotype carriers created a more homogeneous case group and provided an opportunity to uncover the genetic architecture of T2D-ESKD that is independent of APOL1 effect. In the $A P O L 1$-negative model, in addition to replicating ENPP7 identified in the baseline model, two novel loci 


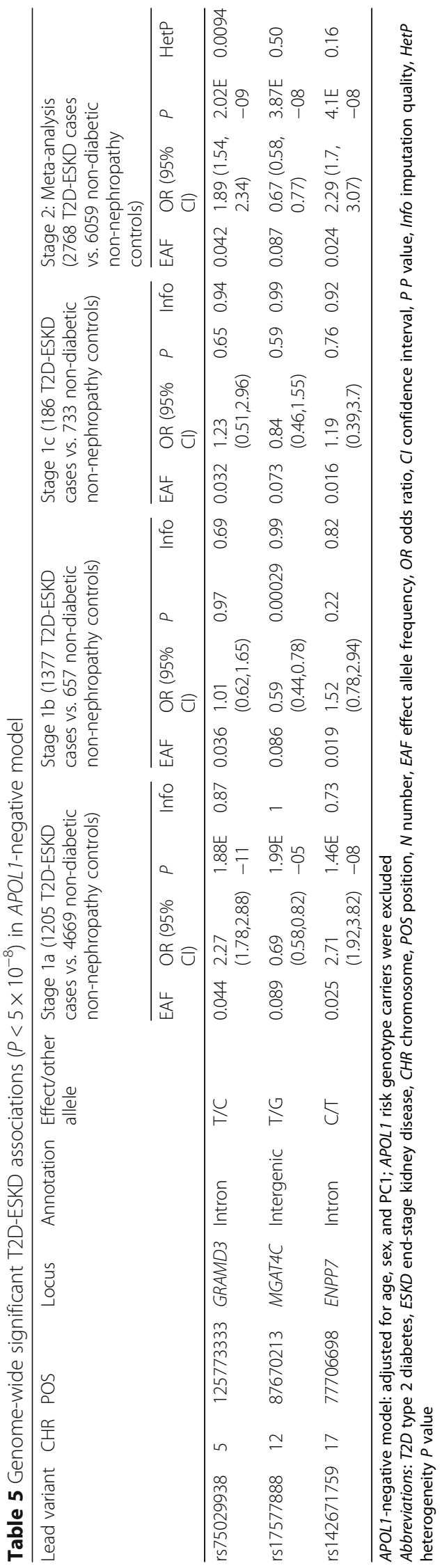




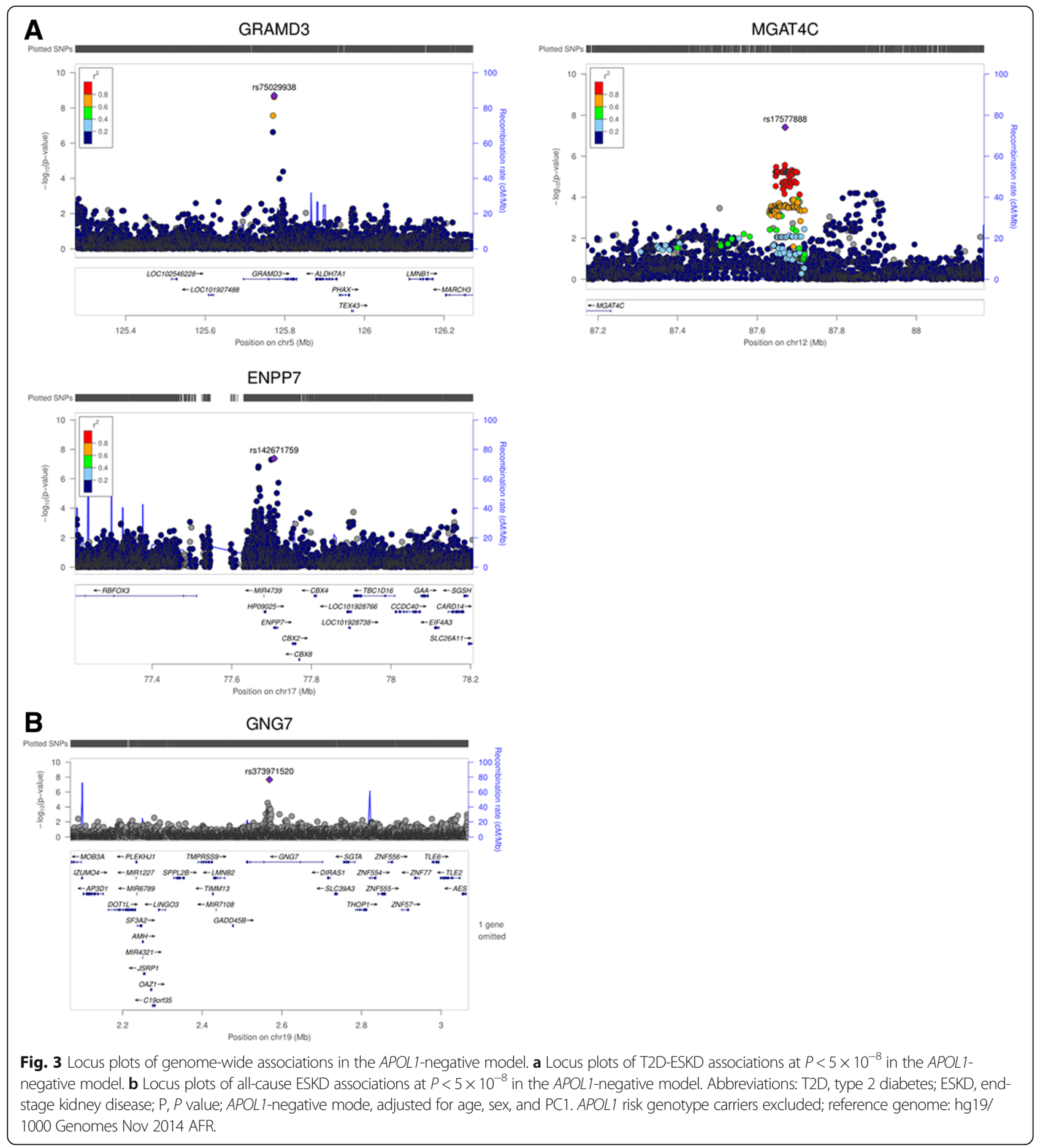

achieved genome-wide significant association with T2DESKD: GRAMD3 (rs75029938; $P=2.02 \times 10^{-9}$ ) and $M G A$ T4C (rs17577888; $\left.P=3.87 \times 10^{-8}\right)$. Functional annotation suggested that both variants are co-located with TF binding motifs. Rs75029938 may fall into enhancer and promoter regions, and rs17577888 was associated with transcript abundance of FLVCR1 gene in peripheral blood monocytes
$\left(P=6.41 \times 10^{-6}\right.$; Additional file 1: Table S6). Genetic variation in GRAMD3 has been associated with adiposity in a multi-ethnic genome-wide meta-analysis [28]. Previous studies suggest that obesity is a major risk factor for DKD [29]. MGAT4C encodes Mannosyl (Alpha-1,3-)-Glycoprotein Beta-1,4- $\mathrm{N}$-Acetylglucosaminyltransferase, Isozyme C, which participates in the transfer of $\mathrm{N}$-acetylglucosamine 
Table 6 All-cause ESKD-associated variants at $P<5 \times 10^{-6}$ in APOL 1-negative model

\begin{tabular}{|c|c|c|c|c|c|c|c|c|c|c|c|c|c|c|c|}
\hline \multirow[t]{2}{*}{ Lead variant } & \multirow[t]{2}{*}{ CHR } & \multirow[t]{2}{*}{ POS } & \multirow[t]{2}{*}{ Locus } & \multirow[t]{2}{*}{$\begin{array}{l}\text { Effect/other } \\
\text { allele }\end{array}$} & \multirow[t]{2}{*}{${ }^{*} \operatorname{lnfo}$} & \multicolumn{3}{|c|}{$\begin{array}{l}\text { Stage 2: Meta-analysis } \\
\text { ( } 2768 \text { T2D-ESKD cases } \\
\text { vs. } 6059 \text { non-diabetic } \\
\text { non-nephropathy } \\
\text { controls) }\end{array}$} & \multicolumn{3}{|c|}{$\begin{array}{l}\text { Stage } 4 \text { (1019 } \\
\text { non-diabetic ESKD } \\
\text { cases vs. } 733 \\
\text { non-diabetic } \\
\text { non-nephropathy } \\
\text { controls) }\end{array}$} & \multicolumn{4}{|c|}{$\begin{array}{l}\text { Stage } 5 \text { (3787 all-cause ESKD } \\
\text { cases vs. } 6059 \text { non-diabetic } \\
\text { non-nephropathy controls) }\end{array}$} \\
\hline & & & & & & EAF & $\begin{array}{l}\text { OR }(95 \% \\
\mathrm{Cl})\end{array}$ & P & EAF & $\begin{array}{l}\text { OR( } 95 \% \\
\text { Cl) }\end{array}$ & P & EAF & $\begin{array}{l}\text { OR }(95 \% \\
\text { Cl) }\end{array}$ & $P$ & HetP \\
\hline rs12472637 & 2 & 30304514 & ALKYPELL & $A / G$ & 0.94 & 0.33 & $\begin{array}{l}0.81(0.74 \\
0.89)\end{array}$ & $\begin{array}{l}6.05 E \\
-06\end{array}$ & 0.36 & $\begin{array}{l}0.8(0.66 \\
0.96)\end{array}$ & 0.019 & 0.33 & $\begin{array}{l}0.82(0.76 \\
0.89)\end{array}$ & $\begin{array}{l}4.47 \mathrm{E} \\
-06\end{array}$ & 0.83 \\
\hline rs76971802 & 3 & 188607071 & $L P P$ & T/C & 0.95 & 0.09 & $\begin{array}{l}1.43(1.24 \\
1.65)\end{array}$ & $\begin{array}{l}1.06 \mathrm{E} \\
-06\end{array}$ & 0.08 & $\begin{array}{l}1.45(1.03, \\
2.05)\end{array}$ & 0.032 & 0.088 & $\begin{array}{l}1.42(1.24 \\
1.62)\end{array}$ & $\begin{array}{l}5.76 \mathrm{E} \\
-07\end{array}$ & 0.93 \\
\hline rs6459733 & 7 & 156930550 & $\begin{array}{l}\text { MNX1-AS1/ } \\
\text { UBE3C }\end{array}$ & $\mathrm{G} / \mathrm{C}$ & 0.97 & 0.39 & $\begin{array}{l}1.25(1.15 \\
0.87)\end{array}$ & $\begin{array}{l}1.32 \mathrm{E} \\
-07\end{array}$ & 0.39 & $\begin{array}{l}1.25(1.03 \\
1.53)\end{array}$ & 0.026 & 0.39 & $\begin{array}{l}1.24(1.15 \\
1.35)\end{array}$ & $\begin{array}{l}7.17 \mathrm{E} \\
-08\end{array}$ & 0.83 \\
\hline rs4910809 & 11 & 3813850 & NUP98 & $C / G$ & 0.98 & 0.02 & $\begin{array}{l}0.53(0.4 \\
0.7)\end{array}$ & $\begin{array}{l}9.46 \mathrm{E} \\
-06\end{array}$ & 0.02 & $\begin{array}{l}0.53(0.29 \\
0.95)\end{array}$ & 0.034 & 0.023 & $\begin{array}{l}0.53 \text { (0.41, } \\
0.69)\end{array}$ & $\begin{array}{l}2.12 \mathrm{E} \\
-06\end{array}$ & 0.63 \\
\hline rs219020 & 13 & 63013622 & $\begin{array}{l}\text { LINC01075/ } \\
\text { LINC00448 }\end{array}$ & $C / T$ & 0.97 & 0.14 & $\begin{array}{l}1.31(1.17 \\
0.86)\end{array}$ & $\begin{array}{l}6.84 \mathrm{E} \\
-06\end{array}$ & 0.11 & $\begin{array}{l}1.38(1.02 \\
1.87)\end{array}$ & 0.037 & 0.14 & $\begin{array}{l}1.31 \text { (1.17, } \\
1.47)\end{array}$ & $\begin{array}{l}2.12 \mathrm{E} \\
-06\end{array}$ & 0.58 \\
\hline rs113452507 & 15 & 37954309 & TMCO5A & $C / G$ & 0.92 & 0.16 & $\begin{array}{l}1.29(1.15 \\
1.45)\end{array}$ & $\begin{array}{l}9.71 E \\
-06\end{array}$ & 0.16 & $\begin{array}{l}1.38(1.07 \\
1.77)\end{array}$ & 0.014 & 0.16 & $\begin{array}{l}1.31(1.18, \\
1.45)\end{array}$ & $\begin{array}{l}8.48 \mathrm{E} \\
-07\end{array}$ & 0.93 \\
\hline rs373971520 & 19 & 2568805 & GNG7 & $-/ C A$ & 0.81 & 0.11 & $\begin{array}{l}1.47(1.28 \\
1.7)\end{array}$ & $\begin{array}{l}8.97 E \\
-08\end{array}$ & 0.11 & $\begin{array}{l}1.39 \text { (1.01, } \\
1.91)\end{array}$ & 0.044 & 0.11 & $\begin{array}{l}1.46(1.28 \\
1.67)\end{array}$ & $\begin{array}{l}2.17 \mathrm{E} \\
-08\end{array}$ & 0.016 \\
\hline rs6094913 & 20 & 46561443 & $\begin{array}{l}\text { SULF2/ } \\
\text { LINC01522 }\end{array}$ & $\mathrm{G} / \mathrm{A}$ & 0.93 & 0.09 & $\begin{array}{l}0.72(0.63, \\
1.6)\end{array}$ & $\begin{array}{l}8.28 \mathrm{E} \\
-06\end{array}$ & 0.10 & $\begin{array}{l}0.67(0.48, \\
0.91)\end{array}$ & 0.012 & 0.092 & $\begin{array}{l}0.72(0.63 \\
0.83)\end{array}$ & $\begin{array}{l}2.5 \mathrm{E} \\
-06\end{array}$ & 0.70 \\
\hline
\end{tabular}

Abbreviations: T2D type 2 diabetes, ESKD end-stage kidney disease, $C H R$ chromosome, $P O S$ position, EAF effect allele frequency, OR odds ratio, $C l$ confidence interval, $P P$ value, $*$ Info imputation quality, Het $P$ heterogeneity $P$ value;

APOL1-negative model: adjusted for age, sex, and PC1; APOL1 risk genotype carriers were excluded

(GlcNAc) to the core mannose residues of $\mathrm{N}$-linked glycans. The potential involvement of MGAT4C in DKD requires further study.

This analysis included a cohort of AAs with non-diabetic ESKD to evaluate the generalizability of T2D-ESKD-associated loci in common forms of CKD. The meta-analysis combining cases with T2D-ESKD and non-diabetic ESKD identified two novel genome-wide significant loci associated with all-cause ESKD in addition to APOL1; rs77113398 near EFNB2 $\left(P=9.84 \times 10^{-9}\right.$; baseline model $)$ and rs373971520 in GNG7 $\left(2.17 \times 10^{-8}\right.$; APOL1-negative model). Rs77113398 overlaps with enhancer, promoter regions, and DNase peaks (Additional file 1: Table S6). Prior genome scans in AAs identified significant evidence for linkage to ESKD on chromosome 13q33 including the EFNB2 region in both diabetic ESKD and non-diabetic ESKD [30, 31]. A follow-up study examined 28 tagging variants spanning 39 kilobases $(\mathrm{kb})$ of the EFNB2 coding region demonstrated nominal associations between two variants and all-cause ESKD [32]. However, these reported variants were not correlated with rs77113398. Ephrin-B2 (EFNB2) is expressed in the developing nephron; interactions between ephrin-B2 and its receptors play an important role in glomerular microvascular assembly [33]. In addition, ephrin-B2 reverse signaling protects against peritubular capillary rarefaction by regulating angiogenesis and vascular stability during kidney injury [34]. Ephrin-B1 also co-localizes with CD2-associated protein (CD2AP) and nephrin at the podocyte slit diaphragm and plays an important role in maintaining barrier function at the slit diaphragm [35]. Ephrin B4 receptor kinase transgenic mice develop glomerulopathy, manifested by fused afferent and efferent arterioles bypassing the glomeruli [36]. Thus, multiple lines of evidence support the potential EFNB2 association with CKD, and it is the most promising causal gene underlying association of rs77113398.

This study has strengths and limitations. Although the multi-stage study design was well-powered including 15,075 AAs, it lacked replication of T2D-ESKD associations, particularly for rare variants. Furthermore, several genome-wide significant signals showed significantly different effect sizes across stages, which was likely attributable to sample size differences across stages, and a consequence of the "winner's curse," a phenomenon describing that the true genetic effect size is overestimated because of the initial positive finding. Future replication is needed to confirm these findings. There are few other existing collections with appropriate samples in AAs; this limited replication efforts. Moreover, it is difficult to exclude all individuals misclassified with DKD due to the frequent lack of kidney biopsies. Therefore, we carefully excluded samples with ESKD attributed to non-diabetic etiologies based on clinical phenotypes and subsequently excluded $A P O L 1$ renal-risk-genotype carriers at high risk 
for non-diabetic ESKD. This should minimize misclassification.

\section{Conclusion}

In conclusion, a GWAS was conducted in AAs with T2D-ESKD and seven genetic loci displayed genomewide significant evidence of association, including in RND3/RBM43, SLITRK3, ENPP7, GNG7, APOL1, GRAMD3, and MGAT4C. Beyond APOL1, EFNB2 and GNG7 were also associated with non-diabetic ESKD and revealed genome-wide significant association with all-cause ESKD. Future investigations including genetic replication and experimental validation of these newly identified associations are required to assess their potential impacts on the biological processes leading to advanced DKD in populations with recent African ancestry.

\section{Methods}

\section{Study participants}

Study participants were recruited by the Wake Forest School of Medicine (WFSM; $N=8052$ ), Family Investigation of Nephropathy and Diabetes (FIND; $N=926$ ), Jackson Heart Study (JHS; $N=1912$ ), Atherosclerosis Risk in Communities Study (ARIC; $N=2221$ ), Coronary Artery Risk Development in Young Adults (CARDIA; $N=912$ ), and Multi-Ethnic Study of Atherosclerosis (MESA; $N=$ 1052). Analyses were approved by local institutional review boards, and all participants provided written informed consent. Cases were considered to have T2D-ESKD, including severe DKD, when diabetes was diagnosed $\geq 5$ years prior to the onset of ESKD or with diabetic retinopathy to ensure adequate T2D duration, with renal replacement therapy, estimated glomerular filtration rate $(\mathrm{eGFR}) \leq 30 \mathrm{ml} / \mathrm{min} / 1.73 \mathrm{~m}^{2}$ (CKD4), or urine albumin to creatinine ratio (UACR) $\geq 300 \mathrm{mg} / \mathrm{g}$ (macroalbuminuria). Participants with CKD4 or macroalbuminuria $(N=138)$ were included as cases given their high risk of developing ESKD. T2D was diagnosed according to American Diabetes Association criteria with a fasting blood glucose $\geq 126 \mathrm{mg} / \mathrm{dl}$, 2-h oral glucose tolerance test glucose $\geq 200 \mathrm{mg} / \mathrm{dl}$, random glucose $\geq 200 \mathrm{mg} / \mathrm{dl}$, use of diabetes medications, or physiciandiagnosed diabetes. Cases with non-diabetic ESKD lacked diabetes (or had T2D for $<5$ years) at the initiation of renal replacement therapy, and ESKD was attributed to chronic glomerular disease (e.g., focal segmental glomerulosclerosis), HIV-associated nephropathy, hypertension, or unknown cause. Patients with ESKD attributed to surgical or urologic causes, polycystic kidney disease, autoimmune disease, hepatitis, IgA nephropathy, membranous glomerulonephritis, membranoproliferative glomerulonephritis, or monogenic kidney diseases were excluded. Non- diabetic non-nephropathy controls included participants without diabetes or kidney disease (eGFR $\geq 60 \mathrm{ml} / \mathrm{min} /$ $1.73 \mathrm{~m}^{2}$ and UACR $<30 \mathrm{mg} / \mathrm{g}$ ). Subjects with T2D-lacking nephropathy had eGFR $\geq 60 \mathrm{ml} / \mathrm{min} / 1.73 \mathrm{~m}^{2}$ and UACR $<30 \mathrm{mg} / \mathrm{g}$.

\section{Sample preparation, genotyping, imputation, and quality control}

The study participants were genome-wide genotyped using three different platforms: (1) 8704 samples recruited from WFSM, ARIC, CARDIA, JHS, MESA, and FIND were genotyped on the Affymetrix Genome-wide Human single nucleotide polymorphism (SNP) array 6.0 (Affy6.0); (2) 3133 samples recruited from WFSM were genotyped on the Affymetrix Axiom Biobank Genotyping Array (Axiom); and (3) 3238 samples recruited from WFSM were genotyped on the Illumina Multi-Ethnic Genotyping Array (MEGA). Quality control and imputation were performed separately by each genotyping platform as described below.

Variants that passed quality control (QC) were imputed to a combined haplotype reference panel including the 1000 Genomes phase 3 cosmopolitan reference panel (October 2014 version) [37] and a version of the African Genome Variation Project (AGVP) reference panel including 640 African ancestry haplotypes kindly provided by the African Partnership for Chronic Disease Research and Wellcome Trust Sanger Institute [38]. Pre-phasing was performed using SHAPEIT2 [39], and imputation was performed using IMPUTE2 [40]. Post-imputation QC was conducted to exclude variants with allele mismatch or with large frequency discrepancy $(\geq 0.2)$ with the reference panel $(0.2 \times$ frequency in EUR $+0.8 \times$ frequency in AFR $)$ and imputation info score $<0.4$. A subset of samples was directly genotyped for $A P O L 1 \mathrm{G} 1$ and $\mathrm{G} 2$ variants using Sequenom (Sequenom, San Diego, CA). The concordance was $95 \%$ with imputed genotypes.

\section{Affy6.0 datasets}

As described previously [41], 1513 T2D-ESKD cases, 5299 non-diabetic non-nephropathy controls, and 1892 T2D non-nephropathy controls from WFSM, FIND, JHS, ARIC, CARDIA, and MESA cohorts were genotyped using Affy6.0 (Table 1). In each study, standard QC measures were applied to exclude variants with call rate $<95 \%$, minor allele frequency (MAF) <0.01, or showing departure from Hardy-Weinberg Equilibrium (HWE) $(P<0.0001)$. Sample QC was performed to exclude subjects with call rates < $95 \%$, DNA contamination, duplicates, or population outliers. Given that CARDIA, JHS, and MESA lacked cases with T2D-ESKD, samples from these studies were combined for imputation and association analyses along with WFSM, FIND, and ARIC. 


\section{Axiom dataset}

At WFSM, 1700 AA cases with T2D-ESKD, 770 AA controls without diabetes or nephropathy, and 663 AA controls with T2D who lacked nephropathy were genotyped on a customized Axiom genotyping array (Table 2). Detailed variant information, custom content design, including fine mapping of candidate regions, genotyping methods, and QC were previously reported [42]. In brief, this array included approximately $264 \mathrm{~K}$ coding variants and insertions/deletions (indels), 70K loss-of-function variants, $2 \mathrm{~K}$ pharmacogenomic variants, $23 \mathrm{~K}$ eQTL markers, 246K multi-ethnic population-based genome-wide tag markers, and $115 \mathrm{~K}$ custom content markers. Variants with call rates $<95 \%$, departure from HWE $(P<0.0001)$, and monomorphic variants were excluded. A total of 724,530 variants were successfully called for downstream QC, imputation, and analyses. Sample QC was performed to exclude individuals with low call rate $(<95 \%)$, gender discordance, DNA contamination, duplication, or population outliers.

\section{MEGA dataset}

At WFSM, 1910 non-diabetic ESKD cases, 219 T2DESKD cases, 201 controls with T2D lacking nephropathy, and 908 non-diabetic non-nephropathy controls were genotyped on the MEGA array (Table 2). This array was designed to improve fine-mapping and functional discovery by increasing variant coverage across multiple ethnicities. The array includes (1) backbone content containing highly informative variants for GWAS and exome analyses in ancestrally diverse populations and (2) custom content used to replicate or generalize index GWAS associations, augment GWAS tagging variants in priority regions, enhance exome content in priority regions, fine-map GWAS loci, identify functional regulatory variants, explore medically important variants, and identify novel variant loci in candidate pathways [43]. Genotyping was performed at WFSM. DNA from cases and controls were equally interleaved on 96-well plates to minimize artifactual errors during sample processing. A total of 48 samples sequenced as part of the 1000 Genomes Project [44] at the Coriell Institute for Medical Research were included in genotyping and had a concordance rate of 98.57\%. Genotype calling was performed using GenomeStudio (Illumina, CA, USA). Variants with missing position, missing allele, allele mismatch, call rates < 95\%, departure from HWE $(P<0.0001)$, frequency difference $>0.2$ comparing with 1000 Genome Project phase 3 reference panel, and monomorphic variants were removed. Multiple probe sets were compared, and only the one with the highest call rate was kept. A total of $1,705,970$ variants were successfully called for downstream QC, imputation, and analyses. Sample QC was performed to exclude individuals with low call rate (<95\%), gender discordance, DNA contamination, duplication, or population outliers. DNA swapping was identified and corrected.

\section{Statistical analysis \\ Discovery stage}

We used a multi-stage study design to identify variants associated with T2D-ESKD and their potential role in all-cause ESKD. In the discovery stage, 3432 T2D-ESKD cases and 6977 non-diabetic non-nephropathy controls from all three datasets were included (Fig. 1). Association analysis was performed for each dataset using a logistic mixed model method implemented in the program GMMAT [45] under an additive genetic model. This method controls for population structure and cryptic relatedness through including a genetic relationship matrix (GRM) estimated from a set of high-quality autosomal variants as a random effect. The principal component analysis was performed using EIGENSOFT [46] for each genotyping platform. The first eigenvector (PC1) along with age and sex was used as covariates. A meta-analysis was performed in the three datasets using a fixed effect inverse variance weighting method implemented in METAL [47]. Suggestive associations for T2D-ESKD with $P<1 \times 10^{-5}$, minor allele count (MAC) $>400$, and heterogeneity $I^{2}<80$ were selected for discrimination analysis.

\section{Discrimination stage}

To determine whether putative T2D-ESKD-associated loci in the discovery stage were driven by associations with T2D per se, a meta-analysis combining 2756 AAs with T2D-lacking nephropathy and 6977 non-diabetic non-nephropathy controls from the three datasets (Affy6.0, Axiom, and MEGA) was performed (stage 3, Fig. 1). Variants showing nominal association $(P<0.05)$ with T2D were excluded to remove T2D-associated variants.

\section{Extension analysis of non-diabetic ESKD and meta-analysis of all-cause ESKD}

Genetic variants showing suggestive association with T2DESKD $\left(P<1 \times 10^{-5}\right)$ but not associated with T2D were examined in a non-diabetic ESKD cohort including 1910 non-diabetic ESKD cases and 908 non-diabetic non-nephropathy controls from the WFSM-MEGA dataset for association with non-diabetic etiologies of kidney disease (stage 4$)$. Variants showing nominal association $(P<0.05)$ were tested in a meta-analysis of all-cause ESKD using all T2D-ESKD, non-diabetic ESKD, and controls from the three datasets $(N=12,319$, Affy6.0, Axiom, MEGA) (Fig. 1). This meta-analysis evaluated whether T2D-ESKD associations 
contributed to the risk of all-cause ESKD. We also looked up our top kidney disease-associated variants for putative association with T2D in AAs from the MEDIA consortium ( $N=15,043$ cases and 22,318 controls); SNPs with $P<0.05$ after multiple comparison corrections were removed.

\section{Exclusion of APOL1 risk genotype carriers}

The APOL1 G1 and G2 alleles contribute to risk for non-diabetic kidney disease $[6,48]$. To minimize misclassification of T2D-ESKD, a second analysis was performed excluding APOL1 two-renal-risk-variant carriers and those with missing APOL1 genotypes from T2DESKD cases and non-diabetic non-nephropathy controls (APOL1-negative model). This analysis reduced the heterogeneity of the population despite reducing sample size and having lower statistical power. Specifically, 308 T2D-ESKD cases and 630 controls from the Affy6.0 datasets, 323 T2D-ESKD cases, and 113 controls from the Axiom dataset, and 33 T2D-ESKD cases and 175 controls from the MEGA dataset were removed. In addition, we removed 891 of 1910 all-cause ESKD cases. This analysis may unmask the effects of other non-diabetic ESKD loci beyond APOL1. Individuals were considered $A P O L 1$ renal-risk-variant carriers if they carried two G1 alleles (rs60910145 G allele, rs73885319 G allele), two G2 alleles (rs143830837, 6 base pair in-frame deletion), or were compound heterozygotes (one G1 and one G2 allele) [6].

\section{Functional characterization}

Proxies of genome-wide significant T2D-ESKD-associated variants $\left(r^{2} \geq 0.7\right.$ in 1000 Genomes AFR population) from the baseline and APOL1-negative models were selected using LDlink [49]. The lead variants and proxies were then queried for functional annotations from HaploReg [50], which included chromatin state and protein binding annotation from the Roadmap Epigenomics [51] and ENCODE projects [52], sequence conservation across mammals, the effect of variants on regulatory motifs, and gene expression from eQTL studies.

\section{Additional file}

Additional file 1: Figure S1. QQ plot of GWAS results of T2D-ESKD vs. non-diabetic non-nephropathy controls under baseline model. Figure S2. $P$ value comparisons between baseline, APOL1-negative, and APOL1adjusted models. Table S1. Study description. Table S2. Genome-wide significant variants associated with T2D-ESKD at Stage 2 Meta-analysis. Table S3. Discrimination analysis in 2756 T2D-lacking nephropathy individuals and 6977 controls for genome-wide significant T2D-ESKDassociated variants in baseline mode. Table S4. Discrimination analysis in 2756 T2D-lacking nephropathy individuals and 6977 controls for genome-wide significant T2D-ESKD-associated variants in APOL1-negative model. Table S5. Results of APOL1-negative model for top associations identified in baseline model. Table S6. (Excel). Functional annotations of genome-wide significant T2D-ESKD variants and proxies in linkage disequilibrium $\left(r^{2}>0.7\right)$. (ZIP $\left.138 \mathrm{~kb}\right)$

\section{Abbreviations}

AA: African Americans; AGVP: African Genome Variation Project; APOL1: Apolipoprotein L1; ARIC: Atherosclerosis Risk in Communities Study; CARDIA: Coronary Artery Risk Development in Young Adults; CKD: Chronic kidney disease; DKD: Diabetic kidney disease; EA: European Americans; EAF: Effect allele frequency; eGFR : Estimated glomerular filtration rate; ESKD: End-stage kidney disease; FIND: Family Investigation of Nephropathy and Diabetes; GRM: Genetic relationship matrix; GWAS: Genome-wide association analysis; MESA: Multi-Ethnic Study of Atherosclerosis; OR: Odds ratio; PC: Principal component; QC: Quality control; SNP: Single nucleotide polymorphism; T2D: Type 2 diabetes; T2D-ESKD: Type 2 diabetes-attributed kidney disease; UACR: Urine albumin to creatinine ratio; WFSM: Wake Forest School of Medicine

\section{Acknowledgements}

We thank all the study participants for their valuable contributions to the parent studies (ARIC, CARDIA, FIND, JHS, MESA, WFSM). We thank the contributions of investigators and staff of the parent studies for data collection, genotyping, and data analysis.

ARIC

The Atherosclerosis Risk in Communities study has been funded in whole or in part with Federal funds

from the National Heart, Lung, and Blood Institute, National Institutes of Health, Department of Health and Human Services (contract numbers HHSN268201700001I, HHSN268201700002I, HHSN268201700003I, HHSN268201700004I, and HHSN268201700005I), R01HL087641, R01HL086694; National Human Genome Research Institute contract U01HG004402; and National Institutes of Health contract HHSN268200625226C. The authors thank the staff and participants of the ARIC study for their important contributions. Infrastructure was partly supported by Grant Number UL1RR025005, a component of the National Institutes of Health and NIH Roadmap for Medical Research.

CARDIA

The Coronary Artery Risk Development in Young Adults Study (CARDIA) is conducted and supported by the National Heart, Lung, and Blood Institute (NHLBI) in collaboration with the University of Alabama at Birmingham (HHSN268201300025C \& HHSN268201300026C), Northwestern University (HHSN268201300027C), University of Minnesota (HHSN268201300028C), Kaiser Foundation Research Institute (HHSN268201300029C), and Johns Hopkins University School of Medicine (HHSN268200900041C). CARDIA is also partially supported by the Intramural Research Program of the National Institute on Aging (NIA) and an intra-agency agreement between NIA and $\mathrm{NHLBI}$ (AG0005). Genotyping was funded as part of the NHLBI Candidategene Association Resource (N01-HC-65226). This manuscript has been reviewed by CARDIA for scientific content. FIND

This study was also supported by FIND grants U01DK57292, U01DK57329, U01DK057300, U01DK057298, U01DK057249, U01DK57295, U01DK070657, U01DK057303, U01DK070657, U01DK57304, and CHOICE study DK07024 from the NIDDK and in part by the Intramural Research Program of the NIDDK. A list of the members of the FIND Research Group follows (key: *Principal Investigator; ${ }^{* *}$ Co-investigator; \#Program Coordinator; §University of California, Davis; +University of California, Irvine; $¥$ Study Chair). Genetic Analysis and Data Coordinating Center, Case Western Reserve University: *S.K. Iyengar, ${ }^{*}$ R.C. Elston, ${ }^{* *}$ K.A.B. Goddard, ${ }^{* *}$ J.M. Olson, S. lalacci, \# J. Fondran, A. Horvath, R. Igo Jr., G. Jun, K. Kramp, J. Molineros, S.R.E. Quade; Case Western Reserve University: *J.R. Sedor, **J. Schelling, \#A. Pickens, L. Humbert, L. GetzFradley; Harbor-University of California Los Angeles Medical Center: *S. Adler, ${ }^{* *}$ E. Ipp, **+M. Pahl, **§M.F. Seldin, ** S. Snyder, **J. Tayek, \#E. Hernandez, \#J. LaPage, C. Garcia, J. Gonzalez, M. Aguilar; Johns Hopkins University: *M. Klag, ${ }^{*}$ R. Parekh, ${ }^{* *}$ L. Kao, ${ }^{* *}$ L. Meoni, T. Whitehead, \#J. Chester; NIDDK, Phoenix, AZ: *W.C. Knowler, ${ }^{* *}$ R.L. Hanson, ${ }^{* *}$ R.G. Nelson, ${ }^{* *}$ J. Wolford, \#L. Jones, R. Juan, R. Lovelace, C. Luethe, L.M. Phillips, J. Sewemaenewa, I. Sili, B. Waseta; University of California, Los Angeles: *M.F. Saad, ${ }^{*}$ S.B. Nicholas, ${ }^{*}$ Y.-D.I. Chen, ${ }^{* * X}$. Guo, ${ }^{* *}$ J. Rotter, ${ }^{* *}$ K. Taylor, M. Budgett, \#F. Hariri; University of New Mexico, Albuquerque: *P. Zager, *V. Shah, ${ }^{* *}$ M. Scavini, \#A. Bobelu; University of Texas Health Science Center at San Antonio: ${ }^{*} \mathrm{H}$. Abboud, ${ }^{* *} \mathrm{~N}$. Arar, ${ }^{* *} \mathrm{R}$. 
Duggirala, ${ }^{* * B . S}$. Kasinath, ${ }^{* * F}$. Thameem, ${ }^{* * M}$ M. Stern; Wake-Forest University: ${ }^{*} \neq$ B.I. Freedman, ${ }^{* *}$ D.W. Bowden, ${ }^{* *}$ C.D. Langefeld, ${ }^{*}$ S.C. Satko, ${ }^{*}$ S.S. Rich, \#S. Warren, S. Viverette, G. Brooks, R. Young, M. Spainhour; Laboratory of Genomic Diversity, National Cancer Institute, Frederick, MD: ${ }^{*}$ C. Winkler, ${ }^{* *}$ M.W. Smith, M. Thompson, \#R. Hanson, B. Kessing; Minority Recruitment Centers: Loyola University: *D.J. Leehey, \#G. Barone; University of Alabama at Birmingham: *D. Thornley-Brown, \#C. Jefferson; University of Chicago: *O.F. Kohn, \#C.S. Brown; NIDDK program office: J.P. Briggs, P.L. Kimmel, R. Rasooly; External Advisory Committee: D. Warnock (chair), L. Cardon, R. Chakraborty, G.M. Dunston, T. Hostetter, S.J. O'Brien (ad hoc), J. Rioux, R. Spielman. We acknowledge the contributions of the Wake Forest participants and coordinators Joyce Byers, Carrie Smith, Mitzie Spainhour, Cassandra Bethea, and Sharon Warren and the contributions of FIND participants and physicians and CHOICE patients, staff, laboratory, and physicians at Dialysis Clinic Inc. and Johns Hopkins University.

JHS

The Jackson Heart Study is supported and conducted in collaboration with Jackson State University (HHSN268201300049C and HHSN268201300050C), Tougaloo College (HHSN268201300048C), and the University of Mississippi Medical Center (HHSN268201300046C and HHSN268201300047C) contracts from the National Heart, Lung, and Blood Institute (NHLBI) and the National Institute for Minority Health and Health Disparities (NIMHD). The authors thank the participants and data collection staff of the Jackson Heart Study. The views expressed in this manuscript are those of the authors and do not necessarily represent the views of the National Heart, Lung, and Blood Institute; the National Institutes of Health; or the US Department of Health and Human Services.

MESA

MESA and the MESA SHARe project are conducted and supported by the National Heart, Lung, and Blood Institute (NHLBI) in collaboration with MESA investigators. Support for MESA is provided by contracts

HHSN2682015000031, N01-HC-95159, N01-HC-95160, N01-HC-95161, N01-HC95162, N01-HC-95163, N01-HC-95164, N01-HC-95165, N01-HC-95166, N01-HC95167, N01-HC-95168, N01-HC-95169, UL1-TR-000040, UL1-TR-001079, UL1TR-001420, UL1-TR-001881, and DK063491. Funding for SHARe genotyping was provided by NHLBI Contract N02-HL-64278. Also, supported in part by the National Center for Advancing Translational Sciences, CTSI grant UL1TR001881, and the National Institute of Diabetes and Digestive and Kidney Disease Diabetes Research Center (DRC) grant DK063491 to the Southern California Diabetes Endocrinology Research Center. Genotyping was performed at Affymetrix (Santa Clara, CA, USA) and the Broad Institute of Harvard and MIT (Boston, MA, USA) using the Affymetrix Genome-Wide Human SNP Array 6.0.

WFSM

In Wake Forest School of Medicine (WFSM), genotyping services were provided by the Center for Inherited Disease Research (CIDR). CIDR is fully funded through a federal contract from the National Institutes of Health to The Johns Hopkins University, contract number HHSC268200782096C. The work at Wake Forest was supported by NIH grants K99 DK081350 (NDP), R01 DK066358 (DWB/MCYN), R01 DK053591 (DWB), R01 DK087914 (MCYN), U01 DK105556 (MCYN), R01 HL56266 (BIF), R01 DK070941 (BIF) and in part by the General Clinical Research Center of the Wake Forest School of Medicine grant M01 RR07122.

\section{Funding}

ARIC has been funded in whole or in part with Federal funds from the National Heart, Lung, and Blood Institute, National Institutes of Health, Department of Health and Human Services (contract numbers HHSN2682017000011, HHSN2682017000021, HHSN2682017000031, HHSN268201700004I and HHSN268201700005I), R01HL087641, R01HL086694; National Human Genome Research Institute contract U01HG004402; and National Institutes of Health contract HHSN268200625226C. Infrastructure was partly supported by Grant Number UL1RR025005, a component of the National Institutes of Health and NIH Roadmap for Medical Research. CARDIA is conducted and supported by the National Heart, Lung, and Blood Institute (NHLBI) in collaboration with the University of Alabama at Birmingham (HHSN268201300025C \& HHSN268201300026C), Northwestern University (HHSN268201300027C), University of Minnesota (HHSN268201300028C), Kaiser Foundation Research Institute (HHSN268201300029C), and Johns Hopkins University School of Medicine (HHSN268200900041C). CARDIA is also partially supported by the Intramural
Research Program of the National Institute on Aging (NIA) and an intraagency agreement between NIA and NHLBI (AG0005). Genotyping was funded as part of the NHLBI Candidate-gene Association Resource (NO1-HC65226).

FIND is supported by grants U01DK57292, U01DK57329, U01DK057300, U01DK057298, U01DK057249, U01DK57295, U01DK070657, U01DK057303, U01DK070657, U01DK57304 and CHOICE study DK07024 from the NIDDK and in part by the Intramural Research Program of the NIDDK.

JHS is supported and conducted in collaboration with Jackson State University (HHSN268201300049C and HHSN268201300050C), Tougaloo College (HHSN268201300048C), and the University of Mississippi Medical Center (HHSN268201300046C and HHSN268201300047C) contracts from the National Heart, Lung, and Blood Institute (NHLBI) and the National Institute for Minority Health and Health Disparities (NIMHD).

Support for MESA is provided by contracts HHSN268201500003I, N01-HC95159, N01-HC-95160, N01-HC-95161, N01-HC-95162, N01-HC-95163, N01-HC95164, N01-HC-95165, N01-HC-95166, N01-HC-95167, N01-HC-95168, N01-HC95169, UL1-TR-000040, UL1-TR-001079, UL1-TR-001420, UL1-TR-001881, and DK063491. Funding for SHARe genotyping was provided by NHLBI Contract N02-HL-64278. Also, supported in part by the National Center for Advancing Translational Sciences, CTSI grant UL1TR001881, and the National Institute of Diabetes and Digestive and Kidney Disease Diabetes Research Center (DRC) grant DK063491 to the Southern California Diabetes Endocrinology Research Center.

The genotyping services of WFSM were provided by CIDR, which is fully funded through a federal contract from the National Institutes of Health to The Johns Hopkins University, contract number HHSC268200782096C. The work at Wake Forest was supported by NIH grants K99 DK081350 (NDP), R01 DK066358 (DWB/MCYN), R01 DK053591 (DWB), R01 DK087914 (MCYN), U01 DK105556 (MCYN), R01 HL56266 (BIF), R01 DK070941 (BIF) and in part by the General Clinical Research Center of the Wake Forest School of Medicine grant M01 RR07122.

\section{Availability of data and materials}

The datasets used and/or analyzed during the current study are available from the corresponding author on reasonable request.

\section{Authors' contributions}

MG and MCY designed the study. MG performed data analysis and drafted the manuscript. BIF, DWB, NDP, and LM helped to design the study and interpret the results. PJH performed APOL1 genotyping. LD and JX performed server administration and data management. JMK, SKD, YIC, JC, $M F, N F, H K, C D L, J C M, R S P, W S P, L J R, S S R$, JIR, JRS, DT, AT, JGW, and FIND Consortium performed data collection. All authors read and approved the final manuscript.

\section{Ethics approval and consent to participate}

Analyses were approved by local institutional review boards, and all participants provided written informed consent.

\section{Consent for publication}

Not applicable.

\section{Competing interests}

Wake Forest University Health Sciences and Barry Freedman have rights to an issued US patent related to APOL1 gene testing. Dr. Freedman is a consultant for lonis and AstraZeneca Pharmaceuticals.

The other authors declare that they have no competing interests. The funders had no role in study design, data collection and analysis, decision to publish, or preparation of the manuscript.

\section{Publisher's Note}

Springer Nature remains neutral with regard to jurisdictional claims in published maps and institutional affiliations.

\section{Author details}

${ }^{1}$ Center for Genomics and Personalized Medicine Research, Wake Forest School of Medicine, Winston-Salem, NC, USA. ${ }^{2}$ Center for Diabetes Research, Wake Forest School of Medicine, Winston-Salem, NC, USA. ${ }^{3}$ Department of Biochemistry, Wake Forest School of Medicine, Winston-Salem, NC 27157, USA. ${ }^{4}$ Department of Internal Medicine, Section on Nephrology, Wake Forest 
School of Medicine, Winston-Salem, NC, USA. ${ }^{5}$ Department of Internal Medicine, Section on Endocrinology, Wake Forest School of Medicine, Winston-Salem, NC, USA. Institute for Translational Genomics and Population Sciences, Los Angeles Biomedical Research Institute at Harbor-UCLA Medical Center, Torrance, CA, USA. 'Department of Epidemiology, Johns Hopkins Bloomberg School of Public Health, Baltimore, MD, USA. ${ }^{8}$ Institute of Molecular Medicine, University of Texas Health Science Center at Houston, Houston, TX, USA. ${ }^{9}$ Department of Epidemiology, Gillings School of Public Health, University of North Carolina at Chapel Hill, Chapel Hill, NC, USA. ${ }^{10}$ Departments of Public Health Sciences and Medicine, Division of Nephrology and Hypertension, Loyola University Chicago, Maywood, IL, USA. "'Department of Medicine, Hines Veteran's Affairs Medical Center, Hines, IL, USA. ${ }^{12}$ Center for Public Health Genomics, Division of Public Health Sciences, Wake Forest School of Medicine, Winston-Salem, NC, USA. ${ }^{13}$ Department of Biostatistical Sciences, Division of Public Health Sciences, Wake Forest School of Medicine, Winston-Salem, NC, USA. ${ }^{14}$ Center for Public Health Genomics, University of Virginia, Charlottesville, VA, USA.

${ }^{15}$ Departments of Paediatrics and Medicine, Hospital for Sick Children, University Health Network and the University of Toronto, Toronto, ON, Canada. ${ }^{16}$ Department of Preventive Medicine, Center for Genetic Medicine, Northwestern University Feinberg School of Medicine, Chicago, IL, USA.

${ }^{17}$ Division of Genomic Outcomes, Departments of Pediatrics and Medicine, Los Angeles Biomedical Research Institute at Harbor-UCLA Medical Center, Torrance, CA, USA. ${ }^{18}$ Molecular Medicine, Cleveland Clinic Lerner College of Medicine, Cleveland, OH, USA. ${ }^{19} \mathrm{Glickman}$ Urology and Kidney Institute, Lerner Research Institute, Cleveland Clinic, Cleveland, OH, USA. ${ }^{20}$ Nephrology, University of Alabama Birmingham, Birmingham, AL, USA. ${ }^{21}$ Department of Physiology and Biophysics, University of Mississippi Medical Center, Jackson, MS, USA.

\section{Received: 21 December 2018 Accepted: 11 April 2019}

Published online: 15 May 2019

\section{References}

1. United States Renal Data System. 2016 USRDS annual data report: Epidemiology of kidney disease in the United States. National Institutes of Health, National Institute of Diabetes and Digestive and Kidney Diseases, Bethesda, MD, 2016

2. de Boer $\mathrm{IH}$, Rue TC, Hall YN, et al. Temporal trends in the prevalence of diabetic kidney disease in the United States. JAMA. 2011;305:2532-9.

3. Spray BJ, Atassi NG, Tuttle AB, et al. Familial risk, age at onset, and cause of end-stage renal disease in white Americans. J Am Soc Nephrol. 1995;5: 1806-10.

4. Freedman $B$ I, Tuttle AB, Spray BJ. Familial predisposition to nephropathy in African-Americans with non-insulin-dependent diabetes mellitus. Am J Kidney Dis. 1995;25:710-3.

5. Tzur S, Rosset $\mathrm{S}$, Shemer R, et al. Missense mutations in the APOL1. Hum Genet. 2010;128:345-50.

6. Genovese G, Friedman DJ, Ross MD, et al. Association of trypanolytic ApoL1 variants with kidney disease in African Americans. Science. 2010;329:841-5.

7. Kopp JB, Nelson GW, Sampath K, et al. APOL1 genetic variants in focal segmental glomerulosclerosis and HIV-associated nephropathy. JASN. 2011; 22:2129-37.

8. Kottgen A, Pattaro C, Boger CA, et al. Multiple new loci associated with kidney function and chronic kidney disease: the CKDGen consortium. Nat Genet. 2010;42:376-84.

9. Pattaro C, Kottgen A, Teumer A, et al. Genome-wide association and functional follow-up reveals new loci for kidney function. PLoS Genet; 8. Epub ahead of print March 2012. https://doi.org/10.1371/journal.pgen. 1002584.

10. Pattaro C, Teumer A, Gorski M, et al. Genetic associations at 53 loci highlight cell types and biological pathways relevant for kidney function. Nat Commun. 2016;7:10023.

11. Tin A, Colantuoni E, Boerwinkle $E$, et al. Using multiple measures for quantitative trait association analyses: application to estimated glomerular filtration rate (eGFR). J Hum Genet. 2013:58:461-6.

12. Maeda S. Genome-wide search for susceptibility gene to diabetic nephropathy by gene-based SNP. Diabetes Res Clin Pract. 2004;66:S45-7.

13. Pezzolesi MG, Poznik GD, Mychaleckyj JC, et al. Genome-wide association scan for diabetic nephropathy susceptibility genes in type 1 diabetes. Diabetes. 2009;58:1403-10.
14. McDonough CW, Palmer ND, Hicks PJ, et al. A genome wide association study for diabetic nephropathy genes in African Americans. Kidney Int. 2011;79:563-72.

15. Sandholm N, Salem RM, McKnight AJ, et al. New susceptibility loci associated with kidney disease in type 1 diabetes. PLoS Genet. 8. Epub ahead of print September 2012. https://doi.org/10.1371/journal.pgen. 1002921.

16. Sandholm N, Zuydam NV, Ahlqvist E, et al. The genetic landscape of renal complications in type 1 diabetes. JASN. 2017;28:557-74.

17. lyengar SK, Sedor JR, Freedman BI, et al. Genome-wide association and transethnic meta-analysis for advanced diabetic kidney disease: Family Investigation of Nephropathy and Diabetes (FIND). PLoS Genet. 2015;11:e1005352.

18. Mahajan A, Rodan AR, Le TH, et al. Trans-ethnic fine mapping highlights kidney-function genes linked to salt sensitivity. Am J Hum Genet. 2016;99:636-46.

19. Tayo BO, Kramer H, Salako BL, et al. Genetic variation in APOL1 and MYH9 genes is associated with chronic kidney disease among Nigerians. Int Urol Nephrol. 2013;45:485-94.

20. Palmer ND, McDonough CW, Hicks PJ, et al. A genome-wide association search for type 2 diabetes genes in African Americans. PLoS One. 2012; 7:e29202.

21. Zhang $P$, Chen $Y$, Cheng $Y$, et al. Alkaline sphingomyelinase (NPP7) promotes cholesterol absorption by affecting sphingomyelin levels in the gut: a study with NPP7 knockout mice. Am J Physiol Gastrointest Liver Physiol. 2014;306:G903-8.

22. Chang Y-H, Chang D-M, Lin K-C, et al. High-density lipoprotein cholesterol and the risk of nephropathy in type 2 diabetic patients. Nutr Metab Cardiovasc Dis. 2013;23:751-7.

23. Williams AN, Conway BN. Effect of high density lipoprotein cholesterol on the relationship of serum iron and hemoglobin with kidney function in diabetes. J Diabetes Complicat Epub ahead of print 29 March 2017. https:// doi.org/10.1016/j.jdiacomp.2017.03.010.

24. Ceriello A, De Cosmo S, Rossi MC, et al. Variability in HbA1c, blood pressure, lipid parameters and serum uric acid and risk of development of chronic kidney disease in type 2 diabetes. Diabetes Obes Metab Epub ahead of print 21 April 2017. https://doi.org/10.1111/dom.12976.

25. Schwindinger WF, Betz KS, Giger KE, et al. Loss of G protein gamma 7 alters behavior and reduces striatal alpha(olf) level and cAMP production. J Biol Chem. 2003;278:6575-9.

26. Ohta M, Mimori K, Fukuyoshi Y, et al. Clinical significance of the reduced expression of $\mathrm{G}$ protein gamma 7 (GNG7) in oesophageal cancer. Br J Cancer. 2008:98:410-7.

27. Demokan S, Chuang AY, Chang $X$, et al. Identification of guanine nucleotide-binding protein $\gamma^{-7}$ as an epigenetically silenced gene in head and neck cancer by gene expression profiling. Int J Oncol. 2013;42:1427-36.

28. Chu AY, Deng X, Fisher VA, et al. Multiethnic genome-wide meta-analysis of ectopic fat depots identifies loci associated with adipocyte development and differentiation. Nat Genet. 2017:49:125-30.

29. Zoppini G, Targher G, Chonchol M, et al. Predictors of estimated GFR decline in patients with type 2 diabetes and preserved kidney function. CJASN. 2012;7:401-8.

30. Bowden DW, Colicigno CJ, Langefeld CD, et al. A genome scan for diabetic nephropathy in African Americans. Kidney Int. 2004;66:1517-26.

31. Freedman BI, Bowden DW, Rich SS, et al. A genome scan for all-cause end-stage renal disease in African Americans. Nephrol Dial Transplant. 2005;20:712-8.

32. Hicks PJ, Staten JL, Palmer ND, et al. Association analysis of the ephrin-B2 gene in African-Americans with end-stage renal disease. Am J Nephrol. 2008;28:914-20.

33. Takahashi T, Takahashi K, Gerety S, et al. Temporally compartmentalized expression of ephrin-B2 during renal glomerular development. JASN. 2001; 12:2673-82.

34. Kida $Y$, leronimakis $N$, Schrimpf $C$, et al. EphrinB2 reverse signaling protects against capillary rarefaction and fibrosis after kidney injury. J Am Soc Nephrol. 2013;24:559-72.

35. Hashimoto T, Karasawa T, Saito A, et al. Ephrin-B1 localizes at the slit diaphragm of the glomerular podocyte. Kidney Int. 2007;72:954-64.

36. Andres A-C, Munarini N, Djonov V, et al. EphB4 receptor tyrosine kinase transgenic mice develop glomerulopathies reminiscent of aglomerular vascular shunts. Mech Dev. 2003;120:511-6.

37. 1000 Genomes Project Consortium. A global reference for human genetic variation. Nature. 2015;526:68-74. 
38. Gurdasani D, Carstensen T, Tekola-Ayele F, et al. The African genome variation project shapes medical genetics in Africa. Nature. 2015;517:327-32

39. Delaneau O, Marchini J, Zagury J-F. A linear complexity phasing method for thousands of genomes. Nat Methods. 2011;9:179-81.

40. Marchini J, Howie B, Myers S, et al. A new multipoint method for genome-wide association studies by imputation of genotypes. Nat Genet. 2007;39:906-13.

41. Ng MCY, Saxena R, Li J, et al. Transferability and fine mapping of type 2 diabetes loci in African Americans: the Candidate Gene Association Resource Plus Study. Diabetes. 2013;62:965-76.

42. Guan M, Ma J, Keaton JM, et al. Association of kidney structure-related gene variants with type 2 diabetes-attributed end-stage kidney disease in African Americans. Hum Genet. 2016;135:1251-62.

43. Bien SA, Wojcik GL, Zubair N, et al. Strategies for enriching variant coverage in candidate disease loci on a multiethnic genotyping array. PLoS One. 2016:11:e0167758.

44. 1000 Genomes Project Consortium. A map of human genome variation from population-scale sequencing. Nature. 2010;467:1061-73.

45. Chen H, Wang C, Conomos MP, et al. Control for population structure and relatedness for binary traits in genetic association studies via logistic mixed models. Am J Hum Genet. 2016;98:653-66.

46. Patterson N, Price AL, Reich D. Population structure and Eigenanalysis. PLoS Genet. 2006;2:e190.

47. Willer CJ, Li Y, Abecasis GR. METAL: fast and efficient meta-analysis of genomewide association scans. Bioinformatics. 2010;26:2190-1.

48. Freedman BI, Langefeld CD, Lu L, et al. Differential effects of MYH9 and APOL1 risk variants on FRMD3 association with diabetic ESRD in African Americans. PLoS Genet. 2011;7:e1002150.

49. Machiela MJ, Chanock SJ. LDlink: a web-based application for exploring population-specific haplotype structure and linking correlated alleles of possible functional variants. Bioinformatics. 2015;31:3555-7.

50. Ward LD, Kellis M. HaploReg: a resource for exploring chromatin states, conservation, and regulatory motif alterations within sets of genetically linked variants. Nucleic Acids Res. 2012;40:D930-4.

51. Roadmap Epigenomics Consortium. Kundaje a, Meuleman W, et al. integrative analysis of 111 reference human epigenomes. Nature. 2015;518:317-30.

52. The ENCODE Project Consortium. An integrated encyclopedia of DNA elements in the human genome. Nature. 2012;489:57-74.

Ready to submit your research? Choose BMC and benefit from:

- fast, convenient online submission

- thorough peer review by experienced researchers in your field

- rapid publication on acceptance

- support for research data, including large and complex data types

- gold Open Access which fosters wider collaboration and increased citations

- maximum visibility for your research: over $100 \mathrm{M}$ website views per year

At $\mathrm{BMC}$, research is always in progress.

Learn more biomedcentral.com/submissions 